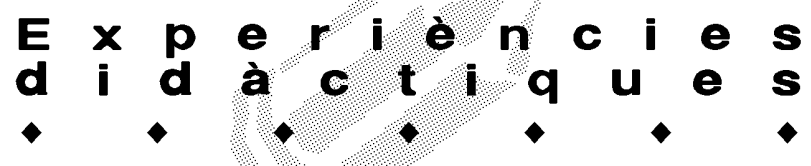

\title{
Posem l'art en joc? \\ Propostes per treballar els jocs populars i tradicionals a partir de la pintura i el gravat
}

\author{
Biel Pubill i Soler. Institut de Flix
}

Resum:

Pieter Bruegel, Guillaume Le Bé, Jacques Stella, Claudinne Bouzonnet i Francisco de Goya tenen en comú, a banda de ser artistes, haver realitzat significatives obres tenint el joc com a tema central. L'anàlisi d'aquestes pintures, gravats i tapissos ens ofereix un ampli i ric ventall iconogràfic de jocs $i$ joguines, representatiu del patrimoni lúdic dels darrers cinc segles. A continuació trobareu un seguit d'experiències, sovint interdisciplinàries, fàcilment aplicables a qualsevol nivell o cicle, que intenten fer que l'aprenentatge resulti realment significatiu i proper, fent que el joc i l'educació física vehiculin una varietat d'activitats que potenciïn el coneixement de la realitat pròpia i el descobriment del patrimoni lúdic col·lectiu.

\section{Paraules clau:}

art, joc tradicional, patrimoni lúdic, valors (diversitat, inclusió, respecte, tolerància).

Sovint, quan miro el quadre Jocs infantils de Pieter Bruegel, em ve al cap la sentència de Johan Huizinga (2000): “Per jugar de debò, I'home, mentre juga, ha de convertir-se en nen."

Estic convençut que Bruegel, mentre el pintava, no sols jugava amb el pinzell, també rememorava la seva infantesa a través dels jocs que havia practicat, de les joguines que s'havia construit o que havia vist i mai no havia pogut aconseguir, recordava com es divertia i distreia amb els amics, somreia encara pensant en les malifetes que havia protagonitzat... i és que a través del joc ens endinsem a la cultura pròpia.

Arreu el joc esdevé el pal de paller entorn del qual s'entra en contacte amb la societat, es construeixen les relacions amb l'entorn i amb la comunitat, i es generen tot tipus de relacions que ajuden a fornir la personalitat. És en aquest sentit que el joc és cultura i alhora, la cultura és joc.

Si atorguem aquesta vàlua al joc quedarà a bastament justificat el fet d'intentar trobar fórmules i recursos per aplicar-lo en l'àmbit educatiu, proposant aplicacions i/o projectes interdisciplinaris, coherents i motivadors que avalin un màxim rendiment.

És amb aquesta perspectiva que, a partir de pintures i gravats creats en els darrers cinc-cents anys, exemplificaré maneres per treballar els jocs populars i tradicionals a l'aula a partir de propostes que es poden vehicular des de l'àrea d'educació física i on podran participar altres matèries com visual i plàstica, història, les llengües o les tecnologies de l'aprenentatge i el coneixement.

\section{Els jocs en l'art}

Figures representant exercicis gimnàstics, equilibris i jocs gravats a les mastabes de Ptahhotep i M ereruka a Sakkara; joguines trobades dins les tombes de l'antic imperi egipci; infinitat de dibuixos d'esplais decorant ceràmiques de I'antiga Grècia; relleus de jocs en sarcòfags d'infants d'època romana; pintures d'igual temàtica en cases de la malaurada Pompeia o mosaics conservats al museu del Bardo, a Tunísia són, sols, alguns exemples generals de 


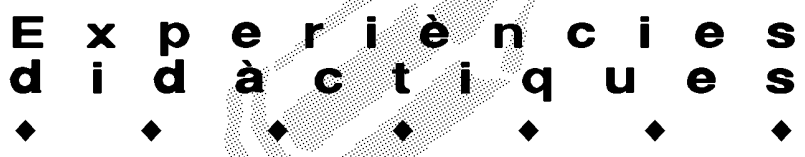

l'extens patrimoni lúdic que ha conservat la història i que, en aquest article, resultaria impossible de llistar. El patrimoni artístic ens ofereix, doncs, un ventall molt ampli d'objectes i imatges de jocs - i fins i tot d'espaisque ens permeten conèixer l'evolució d'aquests al llarg de la història i que, potencialment, poden ser un interessant centre d'interès per conèixer de prop els jocs populars i tradicionals. Aquest vast mostrari obliga a estrènyer l'àmbit d'actuació escollint aquelles obres més representatives, seleccionant una època determinada, comparant obres, autors o períodes...

Les propostes que segueixen se centren en l'anàlisi d'obres d'artistes europeus realitzades a partir del segle XVI. Els suports escollits són els quadres, els tapissos i els gravats que, penso, permeten un examen ràpid de les composicions, un estudi més acurat dels detalls i, en definitiva, una més fàcil observació per a l'alumnat. Artistes sensibilitzats pel món dels jocs i obres de referència que cal tenir present per posar l'art en joc El primer llibre de referència europeu on es descriuen una gran varietat de jocs apareix prematurament al segle XIII: és el famós Libro de acedrex, dados e tablas d'Alfons X el Savi (1283). Es tracta d'un llibre fonamental magníficament il/lustrat- per conèixer i endinsar-se en el món dels jocs de tauler, amb descripcions de jocs de fitxes i daus com ara els escacs, el backgammon, l'alquerc... Malgrat aquest Ilibre primerenc, l'edat mitjana no se significarà per mostrar un interès artístic particular cap al món lúdic i, si bé cada cop són més els gravats, dibuixos i pintures on es representen escenes individuals de jocs, diversions o elements de joc amb imatges de baldufes, cèrcols, xanques, bitlles, sonalls, cavalls de fusta, caminadors, pilotes, nines, gronxadors... en cap moment podrem parlar d'un tractament detallat i específic. No serà fins al Renaixement que descobrim l'impressionant ventall de jocs d'aquest període en tapissos, teles o en petites miniatures dels llibres d'hores - com el de la família Ango o Llibre dels nens, pintat cap al 1500 i on es presenten més de cent jocs infantils.

El vertader artífex que mostrarà amb el màxim esplendor un món il-lustrat de jocs i joguines és l'abans esmentat Pieter Bruegel amb el conegut quadre Jocs infantils (1560). És en aquest moment quan podem assegurar que neix la primera i segurament més important enciclopèdia visual de jocs de tots els temps. Després de Bruegel, altres van seguir-li els passos, encara que mai van arribar a concentrar en un únic quadre la riquesa i diversitat de jocs d'una època.

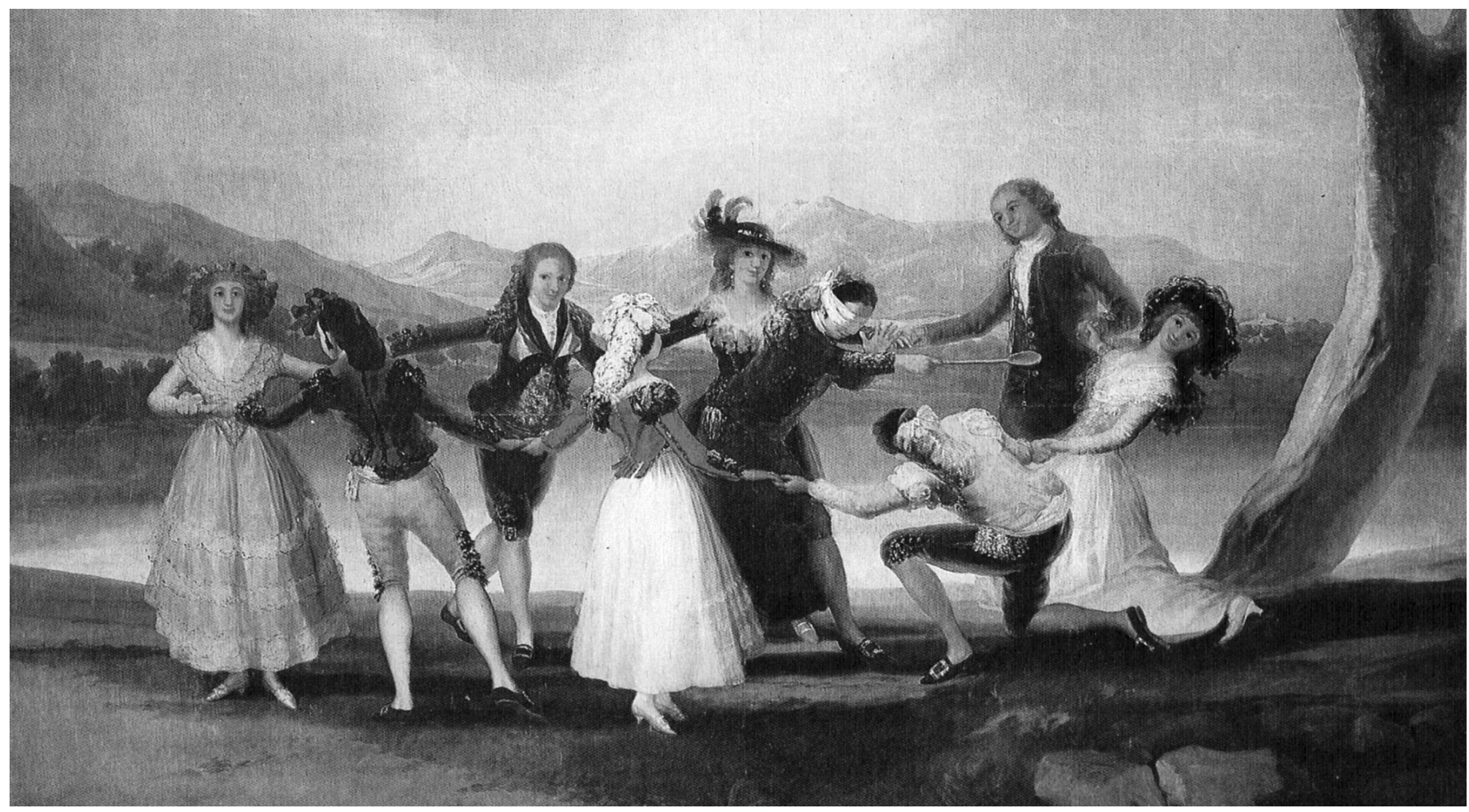




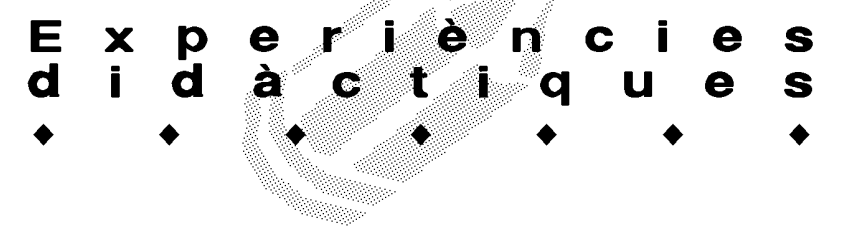

- Pieter Bruegel (1525-1569). Pintor flamenc. -Jocs infantils (1569). Kunsthistorisches Museum de Viena. Pintura que recull més de 90 jocs i que resulta cabdal per treballar els jocs iconogràficament.

-La lluita entre Carnestoltes i la Vella Quaresma (1559). Kunsthistorisches M useum de Viena. Tot i que hi ha pocs jocs (baldufes, xanques, daus, rotlle i algun més) és interessant per contextualitzar la festa i les diversions del segle $\mathrm{XVI}$.

-La kermesse de Hoboken (1559). Museu Calvet d'Avinyó. Com l'anterior, hi trobem sols jocs de taverna tipus flèndit, daus o morra, però il.lustra molt bé la festa popular. Bruegel va fer un dibuix d'aquesta kermesse, amb petites variacions, que va gravar el belga Franz Hogenberg (1535-1590) - col·lecció de la Universitat de Lieja- i que pot servir per fer exercicis de pintar.

- Guillaume Le Bé (1525-1598). Gravador i editor francès.

Les trente-Six figures contenant tous les jeux qui se peuvent jamais inventer et représenter par les enfants, tant garçons que filles, despuis le berceau jusques en l'âge viril (publicat el 1587). Malauradament, d'aquests 36 gravats avui sols en queden 19 a la Biblioteca Nacional de França, i són difícils de consultar.

- Jacques Stella (1596-1657). Gravador francès.

Les jeux et plaisirs de l'enfance (primera edició del 1657). Aquest Ilibre recull $50 \mathrm{il} \cdot$ lustracions més de 70 jocs diferents- d'Stella que va gravar la seva neboda Claudinne Bouzonnet (1636-1697) i que, com veurem més endavant, van donar peu a la còpia i edició d'una de les auques de jocs més conegudes de la península.

- Francisco de Goya (1746-1828). Pintor espanyol.

L'estel, Jugadors de naips, Nens inflant una bufeta de porc, Nens agafant fruita, Nens jugant a soldats, El joc de pilota, El nen de l'arbre, Nens amb mastins, La gallineta cega, Nens pujant a un arbre, Las gigantillas, El pelele, Les xanques i El gronxador es troben al Museu del Prado; El balancí i El potro,al Museu de Belles Arts de València, i La cucanya pertany a una col·lecció privada. Tots aquests quadres, com assenyala Quintana (2002), van ser pintats entre 1777 i 1792, durant l'etapa com a creador de cartons per a tapissos a la Real Fábrica de Santa Bárbara de M adrid. A diferència dels anteriors artistes, Goya no fa cap quadre on apareguin molts jocs, sinó que cal valorar l'obra que tracta el tema del joc en conjunt, que esdevé la imatge més fidedigna, pel context i procedència, per conèixer les diversions $i$ jocs de casa nostra a finals de XVIII i inicis del XIX.

- Gravadors espanyols anònims (des del s. XVII fins avui) A partir del 1670 a Espanya, i en particular a Catalunya i València, neix un dels gèneres literaris populars més emblemàtics. Parlem de les auques - normalment fulls de $42 \mathrm{~cm}$ de llarg per 30,5 cm d'amplada, que duen impresos quaranta vuit quadres distribuitts en vuit rengleres o files de sis vinyetes cadascuna, i que contenen una il|lustració que dóna sentit al motiu o tema de l'auca. S'han conservat nombroses impressions d'una mateixa auca de jocs, la més antiga de les quals, segons I'estudiosa Ana Pelegrin (2006) I'hauria imprès Benet M acé a València l'any 1674 amb el nom de Jochs d'infanteça. En aquesta auca es reprodueixen 48 jocs amb la particularitat que els protagonistes van nus, recordant els famosos putti o àngels italians. Comparant aquests dibuixos amb els gravats al llibre de Claudinne Bouzonnet, no queda cap dubte que el nostre gravador anònim els va copiar de les il/lustracions de l'artista francesa.

Avui no resulta gens difícil trobar una còpia d'aquesta auca en una reedició del llibre Els jocs de la mainada, de Joan Amades (1947) que, com veurem més endavant, resultarà un material preciós per fer diverses activitats en qualsevol nivell educatiu.

Los juegos de la infancia (núm. 64), impresa per M arés l'any 1857 a M adrid, és una altra auca de jocs diferent a l'anterior i que il.lustra a la perfecció els jocs i diversions dels nens i nenes de mitjans de segle XIX - se' $n$ troben moltes reimpressions. 


\section{E.}

Los juegos de la infancia. Segunda parte (núm. 86) impresa el 1865 també per M arés. Aquesta presenta jocs diferents a l'anterior, i no dóna peu a equívoc quant al seu origen espanyol, perquè apareix una vinyeta on els protagonistes figura que toregen un bou.

\section{Posem l'art en joc?}

Fixem-nos, doncs, que des del segle XVI amb Bruegel i Guillaume Le Bé, passant al XVII amb Jacques Stella i Claudinne Bouzonnet, el XVIII amb Francisco de Goya i el XIX amb les diferents impressions d'auques de jocs, disposem d'un ampli i magnífic ventall iconogràfic de jocs i joguines representatiu del món lúdic d'aquestes societats. Anem a veure diferents activitats i projectes, fàcilment adaptables i aplicables a les distintes etapes educatives, que ens permetran treballar les diferents matèries a partir dels jocs que descobrim en l'art.

1. A què jugaven al segle...? La simple observació de qualsevol de les obres abans esmentades ens permetrà fer un ràpid i senzill exercici de descoberta i reconeixement de jocs o joguines en cada època.

a. La comparació entre els jocs d'abans amb els actuals ens permetrà valorar els jocs tradicionals com a part del nostre patrimoni i, des d'àrees com el medi social o natural, contribuirà a construir una línia del temps lúdica que, establint els paral·lelismes, ajudarà a estructurar el pensament històric, o també a entendre que aspectes geogràfics o climàtics, el relleu, la vegetació, el desenvolupament econòmic, entre altres, poden ser factors que influeixin a l'hora de realitzar uns determinats jocs en cada regió.

Si aquesta comparació, en comptes de fer-se per èpoques, es fa analitzant els jocs per l'origen, país o regió europea d'on eren els nostres artistes, - per exemple els personatges de Bruegel amb les vinyetes d'una auca del segle XIX - fomentarem la tolerància i el respecte a la diversitat, ja que entendrem que els jocs no són exclusius d'un grup o d'un indret, i que poden jugar-se de formes diferents i emprant materials diversos.

b. A banda de comparar les il.lustracions, podem fer un treball complementari de recerca, cadascú al seu nivell, preguntant als avis i a les àvies a quins jocs jugaven de

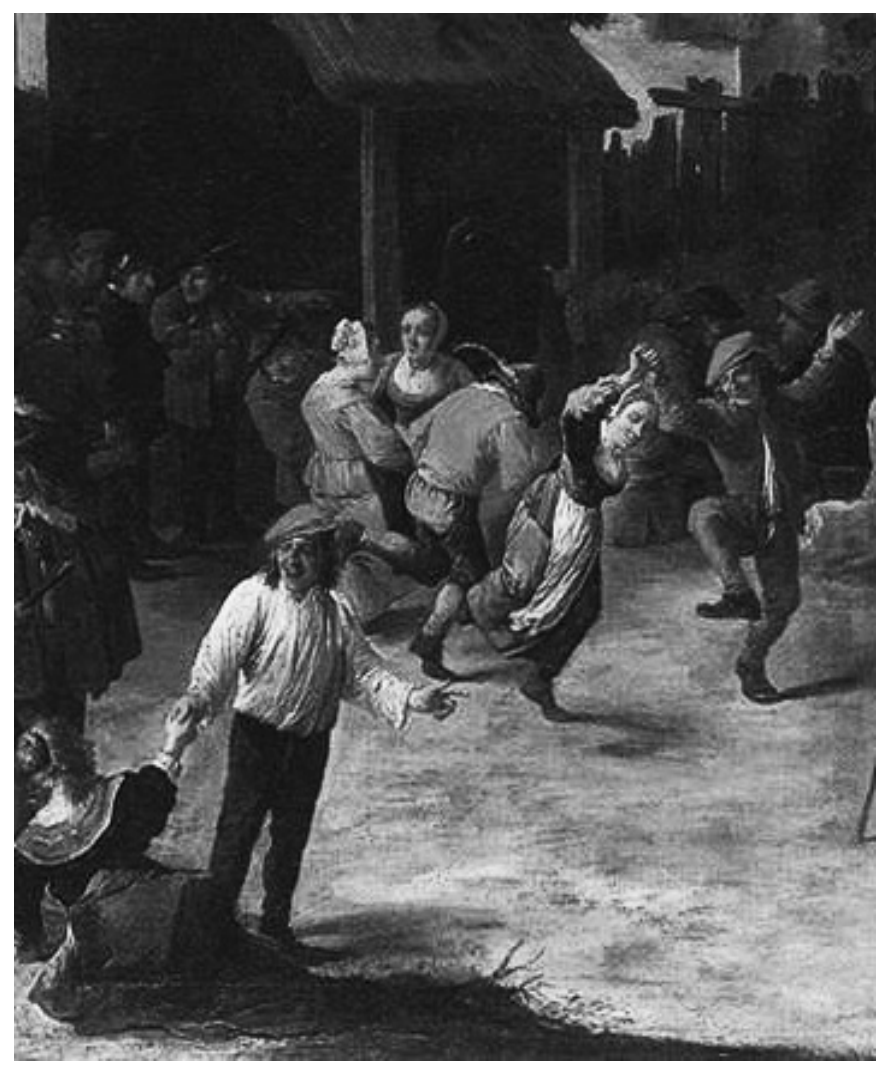

petits, quines eren les regles, quines joguines tenien o es feien, com es divertien... i recollir aquesta informació en un dossier de jocs, enregistrar el so o fer un petit vídeo - estarem treballant aspectes de l'àrea de llengües com ara l'entrevista, la descripció, el diàleg, la memòria... podem fer, fins i tot, un petit conte a partir d'alguna anècdota lúdica o d'algun joc que es reculli. Es pot demanar cercar fotografies familiars on els protagonistes estiguin jugant o presentin alguna joguina. Amb aquest material es faran murals, presentacions orals i es podran utilitzar les noves tecnologies per fer muntatges visuals.

Si hem recollit bé la informació podrem fer un treball conjunt amb els companys de visual i plàstica o tecnologia, construint alguna de les joguines com, per exemple, inofensives pistoles d'agulles, molinets, estels, carretons... En el quadern Els jocs tradicionals a l'aula (2009) hi trobareu exemples de petites joguines que es poden manufacturar de forma senzilla a l'aula.

c. L'àrea de música no s'escapa del projecte. Podeu imaginar $i$ intuir la varietat de jocs cantats que apareixen en els quadres, tapissos i auques indicats. Com a activitat 


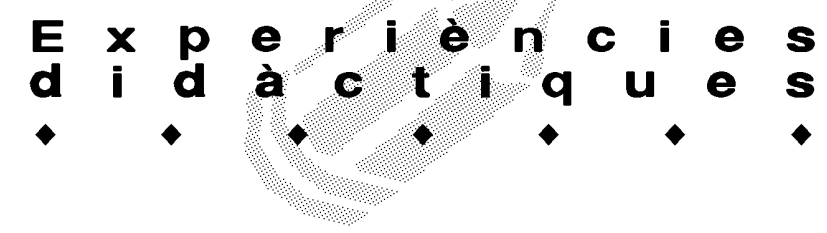

ens podem limitar a fer un recull de les cantarelles i posar en pràctica els jocs - La llengua com a banda sonora del joc (2004) - o també podem buscar un centre d'una altra comarca que es plantegi una recerca semblant i fer una anàlisi comparativa, lingüística i dialectal de les cançons i cantarelles recollides (Pérez i Pubill, 2005); i encara podem anar més enllà i transcriure les melodies d'aquestes cançons i fer un quadern de partitures i, si us animeu, enregistrar-les!

d. Cada artista ens ofereix un ventall impressionant de jocs que, òbviament, posarem en pràctica a l'aula d'educació física. Segur que molts dels jocs els coneixeran. De qualsevol manera, resultarà interessant jugar-los i fer l'exercici de posar-los en pràctica amb els estris o elements de joc que a vegades ens mostren els quadres. En aquest sentit és interessant, per exemple, veure com Bruegel il. lustra el joc de trencar tupins posant l'olla a terra i oferint així l'alternativa als observadors passius de participar directament del joc, tot arriscant-se a agafar el tupí i canviar-lo de lloc!

D'altra banda, segur que hi haurà jocs que els nostres alumnes no sabran reconèixer. Serà també un exercici molt interessant i creatiu veure com proposen formes de jugar, inventades, que podrem posar en pràctica. Aquesta activitat resulta molt enriquidora ja que tothom, individualment o per grup, pot fer aportacions molt divertides que són rebudes amb respecte i atenció pels companys. A partir de l'aplicació d'aquestes noves formes jugades s'estableix, també, un interessant debat de com millorar-les. Relacionar-se, saber escoltar i comunicar-se, respectar el torn de paraula i arribar a un consens en les normes de joc són exercicis i valors que es treballen en aquesta activitat.

2. Jocs tradicionals infantils. Un passeig de 1560 al 2005. Aquest és el títol del projecte dut a terme a l'institut de Flix el curs 2004/05 i que fou reconegut pels Premis Baldiri i Reixac. L'objectiu de l'experiència era reconèixer el món lúdic dels Països Baixos al segle XVI, fer una aplicació pràctica de tots els jocs i recollir i presentar tota la informació emprant les noves tecnologies de la informació. L'activitat va suposar el tractament digital del quadre. Es van retallar totes i cadascuna de les accions de joc que apareixen a la pintura -més de vuitanta. Això vol dir que, com si es tractés d'un trencaclosques, es va trossejar el quadre i amb cada joc es va fer una pàgina externa a la qual es pot accedir clicant damunt la imatge des de la pantalla principal. D'aquesta manera es té accés a aquests més de vuitanta jocs que es presenten amb un mateix disseny: títol, imatge esmicolada del joc pintat per Bruegel, fotografia digital dels alumnes practicant el joc, descripció del joc practicat i una icona que permet tornar a la pàgina principal (La tecnologia al servei de la tradició, 2007).

L'activitat va resultar summament engrescadora, tant pel treball informàtic com per l'aplicació dels jocs. A més, I'alumnat va endur-se el projecte en suport $C D$, amb la qual cosa disposa del recull i alhora un bon record dels companys - podeu trobar el projecte detallat a l'article "De Bruegel a la play!" (2009) i també es pot visualitzar al web de l'IES Flix.

3. Els jocs de la mainada, una auca d'on? La proposta en aquest cas és ben senzilla: comparar les imatges de l'auca d'Amades (1984) amb les làmines gravades per Claudinne Bouzonnet a partir dels dibuixos del seu oncle Stella (1657). Fàcilment els alumnes s'adonaran de la semblança i exactitud de les il.lustracions, i comprendran que els jocs suposadament tradicionals catalans que apareixen a l'auca recollida per Amades estan, realment, inspirats

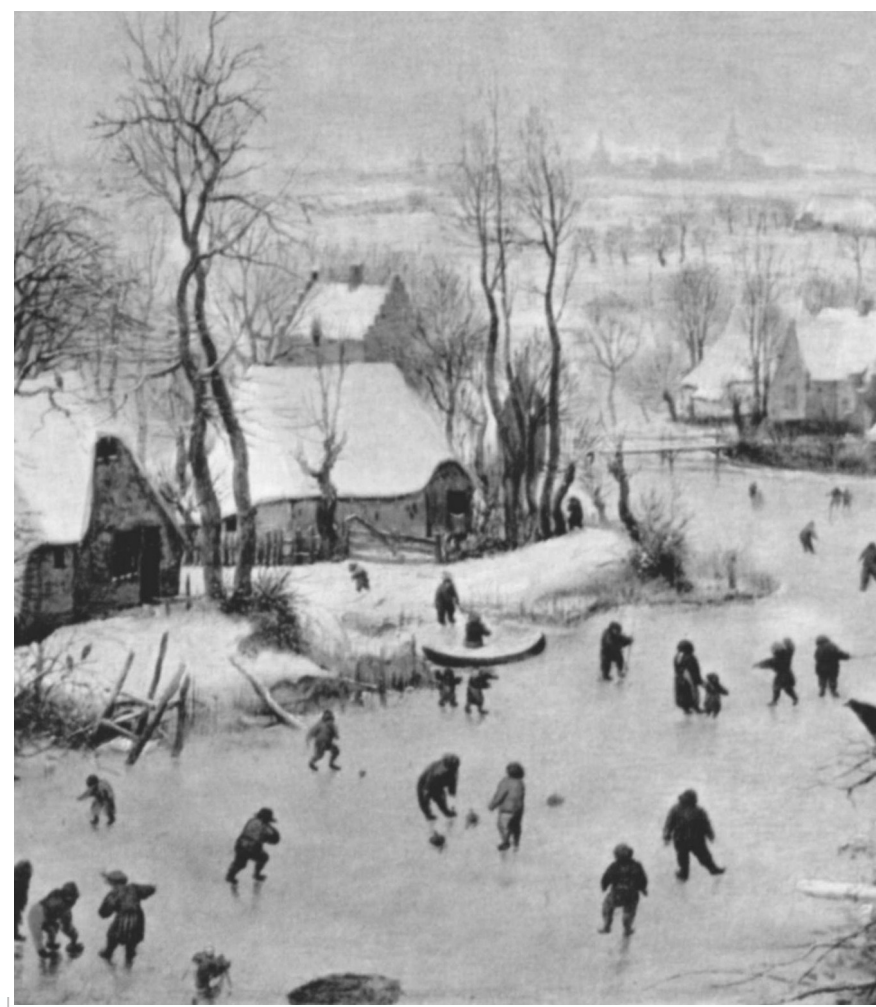




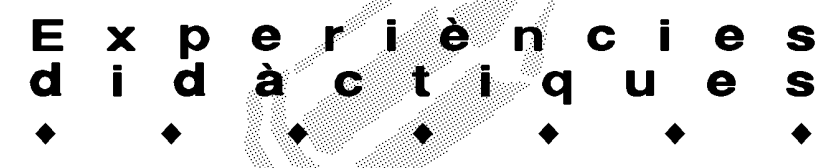

en jocs que es practicaven a França a meitat de segle XVII. Penso que és enriquidor i positiu que els nostres alumnes reflexionin sobre la idea de jocs d'on? jocs de qui? Pot ser un primer pas per treballar valors com la solidaritat, la tolerància o el respecte cap a altres cultures.

4. ¡Niños, ved aquí pintados, vuestros juegos apreciados! o Hay en la primera edad de juegos de gran variedad (títols de la primera vinyeta de les auques Los juegos de la infància impreses per Marés el 1857 i 1865). Un d'aquests podria ser el títol d'un nou projecte centrat, aquest cop, en l'anàlisi de les imatges de les dues auques del segle XIX o també de la recollida per Amades i datada al XVII.

El treball a partir de les auques dóna molt de joc (Ambrós i Pubill, 2008) i ofereix moltes possibilitats de treball interdisciplinari. Amb l'auca podem aplicar tots els exercicis que hem estat exposant fins ara: des de la simple descripció dels jocs fins fer muntatges interactius com el que acabem de descriure. Esdevé una eina molt atractiva per als alumnes per la senzillesa de les il|lustracions i els breus rodolins que les acompanyen. Per aquestes característiques podem dir que les auques permeten vertebrar un interessant projecte per cicles 0 , fins i tot, d'escola, que genera multitud d'activitats. Vegem-ne algunes:

a) Decorar les aules i els passadissos amb auques de diferents temàtiques.

b) Pintar les auques 0 , en el cas dels nens i nenes més petits, fer-ho per vinyetes. A cada nivell es pot treballar amb diferents materials (llapis de colors, aquarel-les, retoladors...) 0 amb tècniques i textures diverses (collage, mosaic, estampat, gravat damunt planxes d'estany 0 plaques de fang...). Aquest treball plàstic permet que els alumnes s'hi fixin molt més, descobreixin detalls i entenguin millor els jocs.

c) Dissenyar la pròpia auca de jocs a partir de fotografies dels nens practicant jocs actuals.

d) Retallar les vinyetes que serviran, com en temps dels nostres avis, com a moneda d'aposta. També podem fer jocs de memòria tot retallant dos auques iguals i posant les vinyetes cara avall. Així mateix, retallant les 48 vinyetes podrem fer jocs de loteria, i encara ens podem inventar jocs com ara "Endevina quin joc sóc" - un exercici d'expressió i creativitat més complicat que suposa que els nens, en petits grups, exercitin la mímica, el gest, el moviment per representar el joc de la vinyeta que els ha tocat. I encara podríem practicar multitud de jocs com ara el flèndit, la porteta, la palmadeta, cara o creu, la ratlleta... (vegeu Els jocs tradicionals a l'aula, 2009).

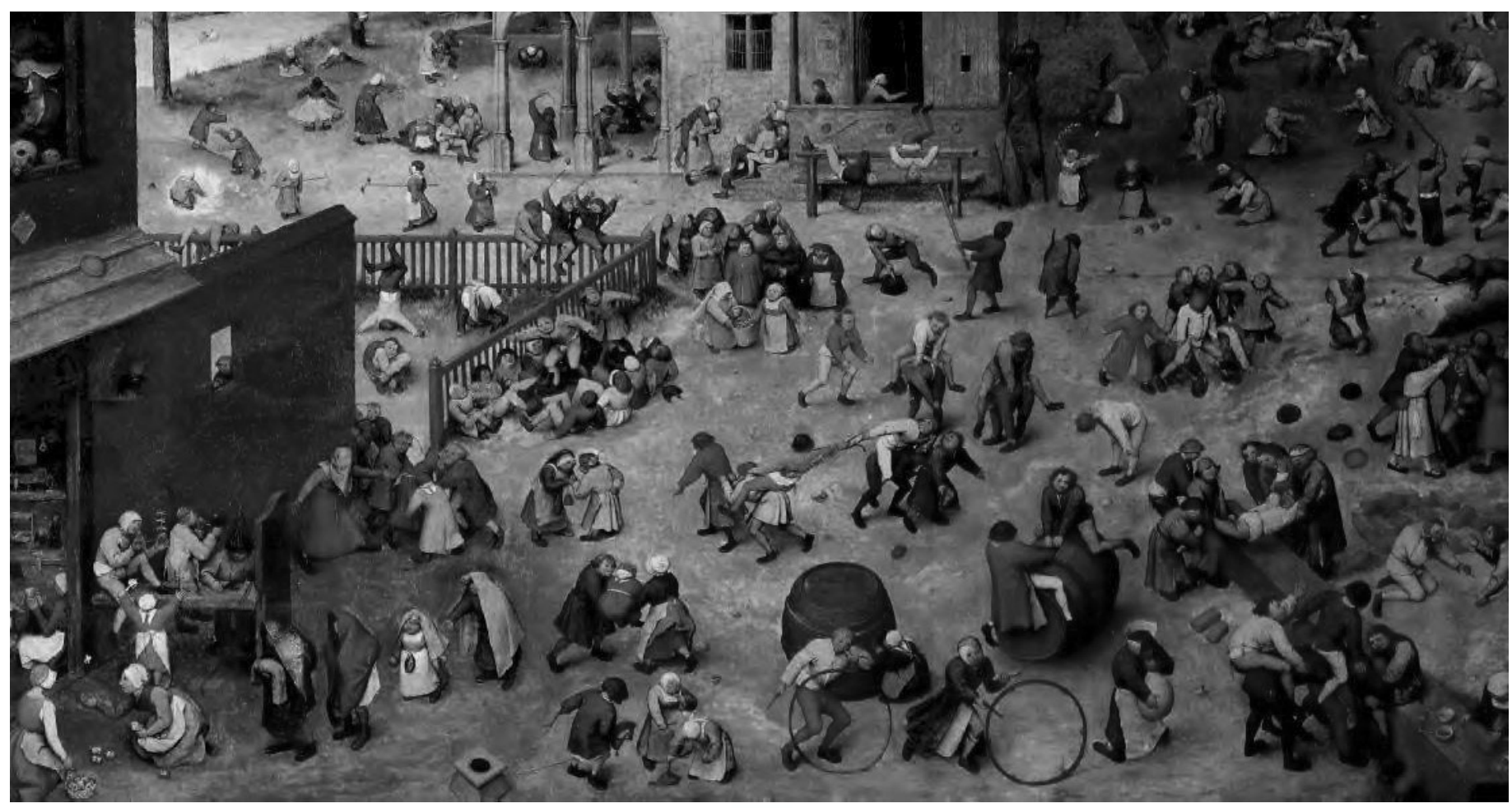




\section{g.}

\section{jocs d'una època o jocs de sempre?}

Totes aquestes activitats confirmen la vàlua que té treballar els jocs tradicionals a partir de la iconografia que apareix en les obres d'artistes excepcionals, com Pieter Bruegel o Goya. Alhora, permet descobrir i analitzar arts menors, com ara els gravats d'Stella o les auques. Aquesta comparança entre l'art d'una minoria privilegiada i la del poble esdevé un enriquiment en tant que permet comprendre que el món lúdic d'uns i altres ha estat, en el fons, el mateix al llarg de la història.

Penso que queda palès que aquest viatge al passat, partint d'una realitat tan propera a l'alumne com és el joc, permet fer un ampli treball interdisciplinari, coherent, des de tots els nivells i cicles. Fa que l'aprenentatge sigui realment significatiu i proper, convertint el joc i l'educació física en eix vertebrador d'una varietat d'activitats que potencien el coneixement de la realitat pròpia, el descobriment del patrimoni lúdic col-lectiu, l'assentament de les bases del raonament del discurs històric i el desenvolupament de l'expressió escrita. A més, gràcies a l'ús de les TAC, conjumina a la perfecció tradició i modernitat.

\section{Referències}

AADD (2009). Els jocs tradicionals a l'aula. Exemple d'aplicació pràctica. Departament d'Educació i Secretaria General de I'Esport de la Generalitat de Catalunya. ALFONSO X EL SAVI (2007). Libro de los juegos: acedrex, dados e tablas: ordenamiento de las tafurerias. Madrid: Fundación José Antonio de Castro.

AM ADES, Joan (1984). Auca dels jocs de la mainada. Barcelona: Editorial Alta Fulla, col·lecció "El pedrís". AM BRÓS, Lourdes; PUBILL, Biel (2008). La cultura lúdica. Una ullada al patrimoni més divertit, VIII Jornades de Pedagogia del Patrimoni Cultural. Consell Comarcal de I'Alt Empordà, 11-17.

HUIZINGA, Johan (2000). Homo ludens. M adrid: Alianza Editorial / Emecé Editores.

PELEGRIN, Ana (2006). La flor de la maravilla. Juegos, romances, retahílas. Fundación Germán Sánchez Ruipérez. PÉREZ, Àngels; PUBILL, Biel (2005). “Les cantarelles dels jocs, recurs per treballar la llengua". GUIX, núm. 311, p.39-47.

PUBILL, Biel (2004). "La llengua com a banda sonora del joc" dins a Actes de la Jornada Llengua i Joc, organitzada pel Centre de Normalització Lingüística de Lleida. Tàrrega: Consell Comarcal de I'Urgell i CRP de I'Urgell. Tàrrega, 7 i 8 de maig de 2004.
[http://www.cpnl.org/xarxa/CNLlleida/urgell/comunica cions.htm]

PUBILL, Biel (2007). "La tecnologia al servei de la tradició: els jocs tradicionals entre la teoria i la pràctica" a Els jocs tradicionals. Recerca i patrimoni etnològic. Institut Ramon M untaner, p. 44-51.

PUBILL, Biel (2009). "De Bruegel a la Play. Un viaje de 450 años a través de juegos infantiles" a TÀNDEM . Didàctica de la Educación Física, núm. 29, p. 97-103. QUINTANA, Alícia (2002). M useo del Prado. Itinerarios para profesores/padres. Cartones de Goya. Madrid: Ministerio de Educación, Cultura y Deporte. Museo Nacional del Prado..

STELLA, Jacques (1990). Juegos y pasatiempos de la infancia. Mallorca: José J. de Olañeta.

Livre d'heures de la famille Ango ou Livre des enfants. Rouen. 1500 [consultable a la Biblioteca Nacional Francesa. Departament de Manuscrits. París, NAL 392, fol. 140].

Fonts de consulta i altres recursos:

www.xtec.es/centres/e3007233/

Web de I'IES Flix on es poden veure els projectes Jocs tradicionals infantils. Un passeig de 12560 al 2005 i L'auca de jocs de Joan Amades.

www.momes.net/coloriages/1299.html

Hi trobareu dibuixat el quadre de Bruegel a punt perquè els vostres alumnes el puguin acolorir.

http:// www.museodelprado.es/uploads/media/Carton es_de_Goya_01.pps Presentació del Museu del Prado on es poden observar els quadres de Goya sobre jocs.

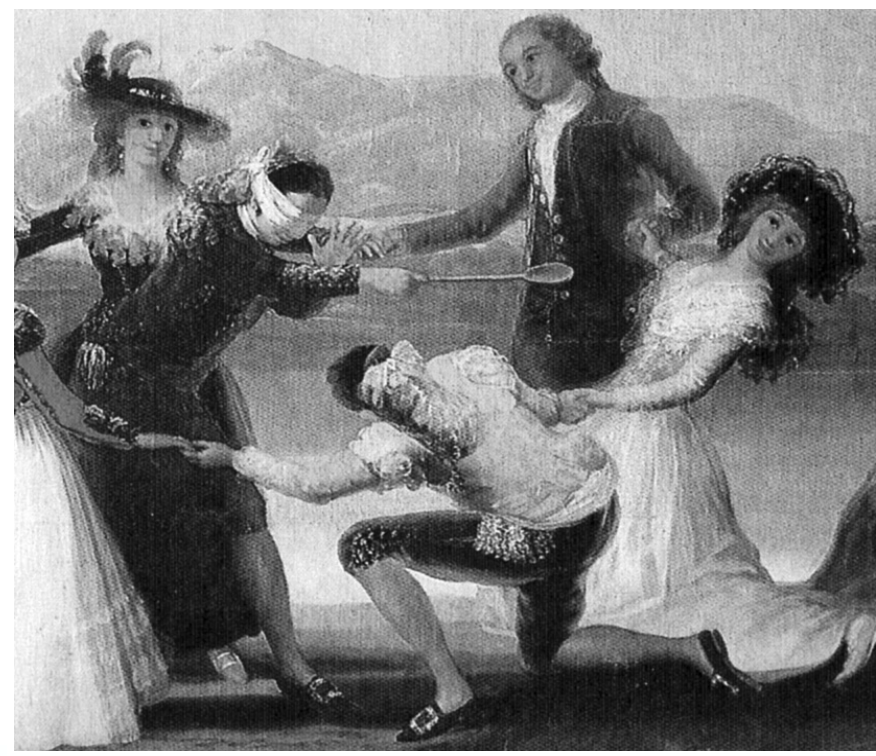

